\title{
FRIDA KAHLO E UMA EDUCAÇÃO INCLUSIVA POTENCIAL
}

\author{
Ana Carolina Sênos e Santos ${ }^{1}$ \\ (D) https://orcid.org/0000-0003-3386-4369 \\ Anna Marina Madureira de Pinho Barbará Pinheiro² \\ (iD) https://orcid.org/0000-0002-3192-3663
}

\begin{abstract}
Resumo: $\mathrm{O}$ artigo visa teorizar sobre a narrativa da pessoa com deficiência como uma temática naturalizada no âmbito escolar como componente curricular na esfera social através das referências artísticas na obra da Frida Kahlo.Faz-se mister informar o conceito de deficiência que é sempre mencionado com eufemismos ou por entrelinhas pelos teóricos que investigam a obra da artista e sugerir o componente de sua orientação sexual LGBTQIA+ para reafirmar o corpo integral em sua obra escrita e imagética e reescrever uma narrativa real despida de afirmações patriarcais da sociedade.Inserir as potencialidades do corpo com deficiência na obra de Frida e desmistificar o fazer artístico e reavaliar as questões do seu trabalho com um viés feminista para um ensino de artes que considera a importância de corpos dissidentes na história da arte mundial e latina.Formar uma consciência dinâmica de corpos deficientes capazes, potentes e ocupantes de todos os espaços sociais e definidores destes espaços e de afetividades incluindo esta corporeidade nas histórias principais da comunidade acadêmica.
\end{abstract}

Palavras-chave: deficiência; Igbtqia+; frida kahlo; educação; artes visuais.

\footnotetext{
${ }^{1}$ Possui graduação em Artes Visuais na Universidade Estadual do Rio de Janeiro e é professora de Artes na rede municipal de Niterói. E-mail: ana.santos@unila.edu.br

2 Professora Associada do Departamento de Ciência Política do IFCS/UFRJ e do Programa de Mestrado em Políticas Públicas em direitos Humanos -PPDH do NEPP-DH/UFRJ. E-mail: annapin09@gmail.com
} 


\section{FRIDA KAHLO AND A POTENTIAL INCLUSIVE EDUCATION}

Abstract: The article aims to theorize about the narrative of the person with disability as a naturalized theme in the school environment as a curricular component in the social sphere through the artistic references in the work of Frida Kahlo. It is necessary to inform the concept of disability that is always mentioned with euphemisms or between the lines by theorists who investigate the artist's work and suggest the component of her LGBTQIA+ sexual orientation to reaffirm the integral body in her written and imagetic work and rewrite a real narrative stripped of patriarchal statements of society. To insert the potentialities of the disabled body in Frida's work and demystify artistic making and re-evaluate the issues of her work with a feminist bias for an arts education that considers the importance of dissident bodies in world and Latin art history. To form a dynamic consciousness of disabled bodies that are capable, powerful, and occupying all social spaces and defining these spaces and affectivities by including this corporeality in the main stories of the academic community.

Keywords: disability; Igbtqia+; frida kahlo; education; visual arts.

\section{FRIDA KAHLO Y UNA POSIBLE EDUCACIÓN INCLUSIVA}

Resumen: El artículo pretende teorizar sobre la narrativa de la persona discapacitada como tema naturalizado en el ámbito escolar como componente curricular en el ámbito social a través de los referentes artísticos en la obra de Frida Kahlo. Es necesario informar el concepto de discapacidad que siempre es mencionado con eufemismos o entre líneas por los teóricos que investigan la obra de la artista y sugieren el componente de su orientación sexual LGBTQIA+ para reafirmar el cuerpo integral en su obra escrita e imaginaria y reescribir una narrativa real despojada de los enunciados patriarcales de la sociedad. Insertar las potencialidades del cuerpo discapacitado en la obra de Frida y desmitificar el hacer artístico y revalorizar los temas de su obra con un sesgo feminista para una educación artística que considere la importancia de los cuerpos disidentes en la historia del arte mundial y latino.Formar una conciencia dinámica de los cuerpos discapacitados capaces, potentes y ocupantes de todos los espacios sociales y definir estos espacios y afectividades incluyendo esta corporalidad en las principales historias de la comunidad académica.

Palabras clave: discapacidad; Igbtqia+; frida Kahlo; la educación; artes visuales. 


\section{Introdução}

A escrita sobre corpos deficientes demanda uma dificuldade muito específica, a pesquisa sobre o campo desconhecido. Naturalizar a deficiência em todos os campos é um ato necessário para que os corpos desviantes, fora do padrão, possam ser também potencializados e protagonizem lugares de destaque em diversas profissões e se mostrem eficientes na vida. Todo este caminho deveria começar pela educação e através da saúde. A ignorância cultivada sobre o corpo deficiente faz com que ele seja sempre inóspito e inédito, um corpo desviante e desviado pelo contexto social integral, desde o reconhecimento individual até o meio social de convívio familiar, privado e público.

Quando Davis (2016) traz a imagem da figura do corpo com deficiência como transgressora por estar como figura de fundo a qualquer outra transgressão possível para diversos tipos de corpos, sugere que o corpo deficiente pode passar por todas as experiências que estes outros corpos passam - LGBTQIA+, médico, criminoso etc - acrescida da "experiência defiça", o que traz um caráter de ser o mesmo e ainda ser o outro, o que nos remete ao conceito de Outsider de (BECKER, 2008), no qual mesmo que a pessoa esteja incluída em alguns fatores sociais ainda será um eterno excluído de tantos outros por incipiência de uma sociedade que escolhe somente os padrões cisbrancoheterossexual constrói códigos calcados numa forma ficcional de gênero e sexualidade como pressupostos de inteligibilidade (BUTLER, 2016) para se constituir, exemplificar e estudar.

Mais profundamente Norbert Elias e John L Scotson também estabelecem o conceito do sujeito estigmatizado (ELIAS; SCOTSON, 2000), que é o que se diz sobre os corpos deficientes em geral, como um mecanismo a priori de identificação para a sociedade, mas extremamente superficial, no qual coloca o indivíduo numa barreira identitária alheia às vivências individuais, causando um aprisionamento entre o que se vive e o que se acha que se vive.

Tendo todas essas assimilações em jogo sobre como lidar com a temática defiça e identitária destes corpos, proponho aqui outra forma de direcionamento para o tema, estudar a narrativa destes corpos através da arte, discernir o fundamento e incluir na obra de 
Santos, A. C. S.; Pinheiro, A. M. M. P. B.

artistas com deficiência física ou até intelectual, seus teores sobre seus corpos e subjetividades, do mesmo modo que o fazem com os artistas, escritores e estudiosos comuns, não deficientes, entender a parte constitutiva da obra que é definida pelo contexto corpóreo e por que não, natural dessa potencialidade excepcional desconhecida e conscientemente ignota, as causas e consequências deste modo de caracterizar estes corpos desviantes e como fazer para incluir de fato esta temática na vida educacional e de saúde da sociedade atual advindo de vozes com seu lugar de fala seja na deficiência, seja através do feminismo, ou das possibilidades da nossa contemporaneidade.

\section{FRIDA KAHLO COMO ESCOLHA}

Por que a especificidade na obra de Frida Kahlo? Esse enfoque vem, pois, é uma obra de uma mulher deficiente, na qual as pessoas inferem seu semblante como sequela ou acidente e nunca como deficiência. A adequação do termo deficiente deve ser mais do que assinalada, mas desencoberta. Além disso é uma pessoa que agrupa muitas outras características de corpos alternativos que também são desviadas de sua figura tão midiatizada e apaixonante: LGBTIA+ e não monogâmica, são outros discursos corpóreos da artista sobre os quais há um silêncio estranho e causador de estranhamento quando citados. O caráter feminista e político de sua imagem é sempre exaltado, mas sem as outras características, que ficam encobertas, o discurso de sua obra também fica esvaziado, junto com sua imagem pública.

Poderia citar diversos outros artistas que por alguma deficiência física ou intelectual tiveram suas obras minimizadas e a característica deficiente de corporalidade dissidentes apagada de suas vivências ou estigmatizada como estranha e ou excêntrica, como também muitos julgam a obra de Frida, mesmo com sua apropriação pela mídia. Escultores como Camille Claudel e Aleijadinho, pintores como Henri Toulouse-Lautrec, Van Gogh, Anitta Malfatti, Arthur Bispo do Rosário, as características depressivas de Chagall e Jean Michel Basquiat, artistas como: Virginia Woolf, Robert Schumann, Friedrich Nietzsche, Francisco de Goya, Ernesto Nazareth, Ludwig van Beethoven entre outros, nunca tiveram seus aspectos dissidentes incorporados de forma explícita e agregadora em suas obras. Tais aspectos 
sempre foram vistos como grotescos ou aberrantes, mas de formas tão indefiníveis que podemos considerá-los inúteis enquanto características potencializadoras de suas obras.

É importante especificar esses fatores pois nem na educação formal de artes nem na graduação, estas características vieram como informações isentas de moral. Na educação em biologia, anatomia e ciências, tais aspectos também não são abordados num contexto de amplitude de informações sobre as deficiências para formar uma linha de pensamento que faça com que estas informações sejam consideradas capacitantes. No tratamento de saúde baseado em um padrão qualquer, desvio é considerado aspecto restritivo. E todos estes ítens agrupados induzem ao silenciamento e à descartabilidade de perspectivas axiomáticas que podem estender as presenças e identidades advindas de deficiências.

Além de tudo faz-se mister o foco no corpo feminino e a forma com que é tratado este corpo, pela medicina. Por isso, Frida, mulher, latino americana, LGBTQIA+, com particularidades inerentes à realidade local do tratamento de saúde (mesmo sem muita diferenciação do tratamento global destes corpos neste momento), pode ser considerada como referência da luta feminista por reconhecimento de corpos femininos e pelo conhecimento e estudo de corpos, não monogâmicos e deficientes.

\section{Conceituações de corpos desviantes através da feminilidade}

Podemos identificar muitas informações sobre a deficiência enquanto objeto de estudo para melhor compreender a falta de mobilização quanto ao tema e o constante desconhecimento e desinformação que aprisionam corpos neste lugar de incapacidade. 0 mesmo aconteceu e acontece ainda com o corpo feminino, porém com mais visibilidade hoje em dia em função das lutas feministas. Alguns exemplos do modo que se construiu a medicalização do corpo feminino ajudam a ilustrar o quanto falta ainda para se naturalizar o corpo com deficiência, em específico o corpo feminino com deficiência e como isto pode ser constitutivo da estrutura de um imaginário social incapacitante destes seres humanos.

Mesmo dentro da multiplicidade de femininxs na atualidade, a constituição unificadora das identidades passa pela mesma orientação de alteridade de identificação 
Santos, A. C. S.; Pinheiro, A. M. M. P. B.

destes corpos. As concepções socialmente construídas de feminilidade foram determinadas pelo patriarcado. E a figura feminina continua tentando se entender para se identificar e se colocar no mundo. O condicionamento dos corpos que sempre se colocou necessário ao convívio social se deu através da especialização da medicina e da conduta privilegiada de uma qualificação e opinião médica sobre as questões do corpo humano e da dualidade saúde $\mathrm{x}$ doença que se deu nas escolas médicas para a implantação do estado moderno e do capitalismo.

A estrutura de poder necessária para a construção do estado moderno primeiramente se apoderou da possibilidade de autonomia mínima feminina para minar qualquer potencialidade mesmo dentro dos núcleos familiares para que acontecesse a instauração do capitalismo. E começou através da vigilância de seus corpos. E com isso reduziu toda potência dos corpos e saúde feminina a meros ventres, ou seja, reprodutores de mais mão-de-obra para o Estado. E o resto de todo conhecimento possível sobre este corpo ficou negligenciado e tratado como fator de impotência e submissão ao sistema que já estava vigente. Como Federici (2017, p. 33) explica à esquerda,

Partindo de uma análise da "política do corpo" as feministas não somente revolucionaram o discurso filosófico e político mas também passaram a revalorizar o corpo. Esse foi um passo necessário tanto para confrontar a negatividade que acarreta a identificação de feminilidade com corporalidade, como para criar uma visão mais holística do que significa ser um ser humano. Essa valorização ganhou várias formas, desde a busca de saberes não dualistas até a tentativa (com feministas que veem a "diferença" sexual como um valor positivo) de desenvolver um tipo de linguagem e de "[repensar] as raízes corporais da inteligência humana".

Esta submissão dos corpos e a dualidade saúde $\mathrm{x}$ doença é o que incide $a$ impotência sobre os corpos defiças também. Estes corpos são vistos como essencialmente doentes e incapazes de produzir para a sociedade, e ainda mais do que isso, são vistos como causa de gastos de saúde, perturbadores ao sistema e estranhos à maioria. E na concepção de Vieira (2015, p. 20) "Deve-se, portanto, entender a medicina, vinculando o seu aspecto 
de saber científico ao de prática social que se constrói, a partir do significado que este saber vai adquirindo por meio das representações sociais que vão sendo (re) elaboradas sobre ele."

Dessa forma a medicina constrói um espaço de saber intocável e indiscutível no qual a ausência de parâmetros para determinar fatores de deficiência também determinam o incapacitismo destes corpos, traduzindo-se em categorizações sociais, psíquicas e até de personalidade para estas pessoas, que as invisibiliza ou pelo menos não dão conta de trajetórias específicas no seu cotidiano, muito menos dão suporte para que este trânsito de saberes e práticas seja possível. Para que a vivência seja inclusiva totalmente e não parcialmente. E ao individualizar este acesso, restringe por gênero, raça e classe, o cuidado e a interferência que estes corpos retornam de benefícios para a sociedade. Acreditando em uma perspectiva intersseccional ao adicionar opressões torna a convivência digna praticamente impossível para que se tenha um destaque positivo no convívio social. Assim, todas as pessoas que conseguem destaque, sempre ocultam algum teor das opressões em detrimento de outra. Como Vieira $(2015$, p. 23) entende a seguir,

[...] o desenvolvimento de tecnologia de intervenção nesse corpo significa exercer apropriação médica dele como um objeto de saber. Isso porque a prática médica é, sobretudo, uma prática intervencionista, e mais que um discurso disciplinador sobre os corpos, teremos nesta área, ao estender sua jurisdição, a efetivação da apropriação.

Esta inserção do corpo deficiente como um problema social despe qualquer outro valor que tenha este corpo, ao passo que as outras pessoas não sabem lidar com as diferenças, pessoas com deficiência ficam despidas de sexualidade, identidade de gênero, expressão deste gênero, orientação sexual, profissão, afetividade e qualquer valor que se tenha, pois a própria deficiência já cria um muro para qualquer interação e único assunto a (não) ser abordado. Uma película limítrofe invisível entre o individual e o coletivo em todos os aspectos cotidianos. Viramos uma entidade biológica determinista de quaisquer ações, afastados dos sentidos, nos quais a presença de dificuldades se torna o assunto principal de 
Santos, A. C. S.; Pinheiro, A. M. M. P. B.

qualquer tema e em qualquer esfera de discussão. Não resumir estes corpos à suas sobrevivências, mas sim possibilitar e contextualizar vivências viris e com sentido.

\section{A Educação e o Reconhecimento da Diversidade Deficiente}

A educação sobre o corpo com deficiência para ele próprio ou para o outro que lida com ele é inexistente. Podemos pensar que de vários modos esta identidade é isenta de reconhecimento em diversos campos de estudo e de vida, logo, ela perpassa o meio social, político e econômico, inclusive. Apesar de inabilidade de lidar com essa subjetividade subalterna, existem pouquíssimas políticas públicas destinadas aos deficientes - Mas elas nem sempre são efetivas e muito menos disseminadas à consulta da população. Refletindo o problema, pensamos em qual seria a origem da invisibilidade do corpo deficiente na sociedade, se parte do teor de reconhecimento das identidades destas pessoas ou da

redistribuição para que estas pessoas se insiram como pessoas ativas em sociedade. A dicotomia entre redistribuição e reconhecimento não deve existir pois é a partir dela que é inutilizado qualquer meio eficaz de mudança desta realidade de impotência. Desde já, devemos salientar a interlocução entre todas as dinâmicas que puderem sustentar uma forma de produzir uma identidade potencial para que esta tenha meios de se manter de forma saudável no cotidiano das populações e assim, valorizar uma integração expressiva que demande exemplos de representatividade e que expanda num imaginário popular a presença de pessoas com deficiência no convívio social.

Devemos através da educação transformar pessoas com teoria crítica suficiente para que estas mesmas transformem a sociedade em que vivem, mas mesmo nestas até hoje, as pessoas com deficiência não se incluem pois justamente não são consideradas atores sociais. São privados de participar como iguais na vida social, ou seja, devemos reunir todos os meios para que haja justiça social para esta população. O reconhecimento partindo de um âmbito privado, do individual a caminho do público e o público reafirmando uma excelência potencial que estimule um progresso individual.

Existem políticas de superação da subordinação que tornam isto possível, porém para que o seja, é essencial mudar os padrões de institucionalidade de valoração cultural 
vigentes, ou seja, mudar como é ensinado às pessoas sobre valor, status e participação social, trabalho funcional, padrões de comportamento e estéticos etc. Fraser (2007, p. 108) entende o reconhecimento como:

[...] uma questão de status significa examinar os padrões institucionalizados de valoração cultural em função de seus efeitos sobre a posição relativa dos atores sociais. Se e quando tais padrões constituem os atores como parceiros, capazes de participar como iguais, com os outros membros, na vida social, aí nós podemos falar de reconhecimento recíproco e igualdade de status. Quando, ao contrário, os padrões institucionalizados de valoração cultural constituem alguns atores como inferiores, excluídos, completamente "os outros" ou simplesmente invisíveis, ou seja, como menos do que parceiros integrais na interação social, então nós podemos falar de não reconhecimento e subordinação de status.

Neste sentido, a forma com que as sociedades mudam é feita através das instituições que deveriam capitanear as sociedades que representam, integralmente. E a educação é o primeiro pilar que interfere sobre os costumes de uma cultura. Muitas sociedades estão a margem de índices de crescimento social pois interferem diretamente na forma com que a educação é distribuída em seus países (as quais deixam que haja interferência de costumes excludentes sobre sua educação, seja por classe, gênero ou raça). Precisamos também analisar os conceitos que estas sociedades dispõem para entender as disparidades que indicam suas desigualdades e pensar como formar cidadãos autônomos que realmente têm a possibilidade de interferir positivamente em suas vivências e nas de outrem, formando uma pirâmide de melhoramento social. Conforme Fraser (2007, p. 108) exprime,

Em todos os casos, conseqüentemente, uma demanda por reconhecimento é necessária. Mas note precisamente o que isso significa: visando a não valorizar a identidade de grupo, mas superar a subordinação, às reivindicações por reconhecimento no modelo de status procuram tornar o sujeito subordinado um parceiro integral na vida social, capaz de interagir com os outros como um par. Elas objetivam, assim, desinstitucionalizar padrões de valoração cultural que impedem a paridade de participação e substituí-los por padrões que a promovam. 
O reconhecimento desta parcela social só irá surgir através de uma escola de pensamento que privilegie um ideal de teoria crítica e não uma educação meramente tecnicista e de cunho capitalista, onde define seus seres sociais como indivíduos com as maiores multiplicidades possíveis, porém que todas elas sejam de reprodução de pensamento, não questionadora, que desvia o valor dos movimentos de sabedoria para as benesses do sistema.

No Brasil, os fundamentos de conhecimentos humanos e biológicos perderam importância e espaço no conteúdo curricular desde a ditadura militar de 1964, e durante 21 anos deste regime, moldou o pensamento de um povo negando seu juízo crítico e civil e toda a forma com que a política e as instituições brasileiras se estabelecem hoje em dia. Mesmo diante resistência popular, a educação suprimida desta parcela populacional e os direitos retirados e negados definem todas as dificuldades dos povos minoritários do país, que a qualquer crise é restringida novamente. Esse momento define também como os educadores em exercício na educação básica tiveram sua formação e definem suas prioridades metodológicas, em como percebem as identidades dos alunos e com quais meios conseguem e se importam em incluir ou acolher as alteridades no contexto escolar.

O sucateamento destes meios de educação é o principal fator de interferência negativa no dia-a-dia estudantil e também o principal motivo de evasão escolar, no caso da ausência na inclusão de corpos deficientes por falta de estrutura física, metodológica e de profissionais adequados a educar esta parcela da população, prefiro adequar ao conceito de exclusão escolar (MATTOS, 2012), na qual o indivíduo não teve a oferta de acesso a direitos básicos de todo cidadão brasileiro por carência do próprio sistema. Onde Mattos (2012, p. 219) defende que,

Para falar de inclusão, torna-se necessário falar de exclusão. Exclusão que se faz pelas imagens adquiridas ao longo de um processo histórico e social do sistema educativo, que, paternalista e assistencialistamente, perpetuou episódios de fracasso escolar nas crianças de classes populares, perpassados em estigmas e estereótipos de carência cultural, de déficit de 
inteligência, de deficiência intelectual e das dificuldades de aprendizagem, passados pelo imaginário social e individual.

Sutilmente passando pelo conceito de Outsider within, utilizado por Patrícia Hill Collings (2016) sobre o pensamento feminista negro para adequar ao sistema educacional que trata o aluno com deficiência como aluno de educação inclusiva por estar em convivência escolar, porém sem ser de fato incluído metodologicamente com todas adequações necessárias às disciplinas ou com a naturalização no tratamento social entre ele e os colegas de classe para integrar e coexistir dentro de todas as demandas de afeto e atenção entre os alunos, mais do que isto, poder virar referência em componentes curriculares através de exemplos de representatividade. Como Nascimento de Mattos exemplifica abaixo:

Porém, a educação inclusiva busca a minimização de qualquer tipo de exclusão, abrindocaminho para que a pessoa possa fazer suas escolhas e decidir seus destinos, sem entendê-los como pessoas que precisam de ajuda, mas como pessoas que têm potencial para, por elas próprias, resolverem suas necessidades e desenvolverem suas potencialidades (MATTOS, 2012, p. 224).

A metodologia educacional diferenciada deve ser considerada como um instrumento de ensino transformador e não como um auxílio extra-classe para os alunos deficientes fora do convívio em sala de aula.

Após considerarmos o aluno deficiente como ator social, também podemos considerar o professor deficiente como um outro ator social importante na comunidade escolar. Tal qual como exemplo de representatividade, mas também como exemplo de eficiência didática para além de qualquer aparência estética diversa. A inserção no currículo disciplinar de temáticas que lidem com a deficiência física e cognitiva só será naturalizada de fato quando a comunidade escolar souber abranger em seu quadro discente e docente pessoas deficientes de forma responsável, segura e ampla. E as mesmas trarão representatividade e lucidez para a inclusão potencial de seus pares. 
Santos, A. C. S.; Pinheiro, A. M. M. P. B.

Ao dar exemplos diversos e demonstrar importâncias múltiplas é possível inferir que mesmo com resultados diferentes, e que através de linguagens variadas - a educação pode captar cada vez mais atores desta comunidade escolar, a qual forma nossa sociedade e transformá-la em uma sociedade com equidade em direitos e deveres, que dê acesso e permanência a todos. Não só através de linguagens didáticas para pluralizar possibilidades de aprendizagem, mas através de novas linguagens de reconhecimento individual e coletivo que abarque qualquer diferença estética, sexual, ou identitária formadora enquanto estudante, um momento criador de consciência crítica, caráter, hábitos e juízo de valor, onde deve ser demonstrado todos os aspectos sociais inerentes ao ser para a real escolha autônoma daquele ser em desenvolvimento. Butler (2018) entende um modelo de discurso-ação que pode considerar este viés e, "Ser constituído pela linguagem é ser produzido dentro de uma dada cadeia de poder/discurso que está aberta à ressignificação, à relocação, à citação subversiva interna e à interrupção e à convergência inadvertida com outras cadeias semelhantes." (BUTLER 2018, p. 167).

Ou seja, quando se mantém uma linguagem restritiva, antiquada que não conversa com os alunos e suas necessidades pessoais de entendimento de ser, logo o modelo educacional se mantém obsoleto e com paradigmas arcaicos de linguagem corporal e padrões ultrapassados à época atual de multiplicidade de reconhecimento. Considerar o aluno como um sujeito em constante modificação de aprendizado também significa considerar um indivíduo com obstinada mudança pessoal de aparelhagem física, psíquica e motora onde todos os assuntos o permeiam integralmente e é neste momento que deve se introduzir os meios de percepção e respeito às diferenças e modos de lidar com estas diferenças. Acima de tudo, a educação deve formar cidadãos e não reprodutores de conteúdos.

As disciplinas devem ser lecionadas com a maior integração possível, e não como é feito hoje, com a separação estrita e a especificidade em mentalizar os conteúdos para que sejam decorados visando uma prova de vestibular ou o mercado profissional desde sempre. Este padrão de ensino causa um amplo conhecimento de disciplinas que parecem muito 
afastadas do cotidiano do aluno, o qual as imagina sem sentido ou importância, principalmente em uma esfera rotineira de carência econômica, social e política. O modelo pós moderno de ensino que visa formar trabalhadores para o sistema capitalista afasta cada vez mais as pessoas da própria subjetividade e amplifica a dificuldade de comunicação interpessoal, causando intolerância e aspereza às diversidades, inviabilizando a construção do ser. Mattos (2012) sugere que a forma de lidar possa ser:

De introduzir a afetividade para enfrentar a exclusão social e, por consequência, escolar. De colocar a felicidade - entendida como centrar-se na humanização - como critério para definir maneiras de inclusão, vista como o cuidado com o outro pela sociedade e pela escola, sem negar sua particularidade em meio à pluralidade de identidades existentes. (MATTOS, 2012, p. 231)

Mesmo que o aluno com deficiência não seja de classes populares, ele enfrenta dificuldades de socialização relativas no campo da afetividade. O espectro da impotência que o define insere uma impraticabilidade para o contato interpessoal pelo aspecto da lacuna do que a pessoa com deficiência não consegue fazer e nunca explicita o parâmetro potencial diverso daquele corpo. Mais do que isso, permite um congelamento das capacidades desta pessoa, como se um fator de claudicação inviabilizasse quaisquer progressões de outras aptidões no qual a única comunicação considerada perspicaz ou válida seja a comunicação oral. O próprio distanciamento espacial e de afetividade já torna inconcebível qualquer troca pessoal. Aquele sujeito fica externo a implicações comuns de convivência e se torna solitário independente de qualquer habilidade inteligível e mantém sua exclusão em sociedade pela inabilidade do outro de lidar com as diferenças.

\section{"O que um corpo pode fazer?"}

Partir de uma reflexão sobre o que um corpo pode fazer a partir de um parâmetro normativo exclui muito mais pessoas do que de fato as integra. Tomando por vias de 
Santos, A. C. S.; Pinheiro, A. M. M. P. B.

exemplos, todos os corpos possuem seus limites e suas possibilidades, o que de fato define as extensões corporais são as inter relações com o outro. Enquanto todos tentam se enquadrar em padrões corporais definidos pela medicina ou padrões estéticos e sociais definidos pelos conceitos da pós modernidade, ou até padrões heteroeurocêntricos de sexualidade, um corpo incapaz de se adequar a qualquer desses padrões se torna marginalizado, e ao adicionar mais opressões relativas a outros determinados padrões que não definidos pelo conceito de saúde, a impossibilidade de adequação só aumenta. As condições pessoais não podem ser nem parecer estáticas, isto faz com que estes padrões se mantenham inegociáveis, inertes e inexpressivos. Toda mudança depende do engajamento social de todos os seus pertencentes em conjunto para que se torne de fato um movimento além do ativismo individual. Relacionar o corpo deficiente à imobilidade além de ser um equívoco sem tamanho, significa retirar qualquer pulsão de coletividade que este pode integrar. Mas Behabib (1992) aponta que "Em qualquer cultura que tenha sido de alguma maneira tocada pelo processo de modernidade, encontramos aqueles que lutaram pela liberdade, igualdade e dignidade humana e aqueles que resistiram a estes chamados." (BENHABIB, 1992, p. 187).

A própria existência da pessoa com deficiência e todos os percalços íntimos, públicos e privados que esta pessoa passa já faz dela uma militante pelo simples fato de querer viver dignamente em sociedade. O corpo que almeja pela potência de vida a todo momento, em condições aquém de qualquer pessoa comum, pretende que esta vida tenha inserção política, econômica e social mesmo com mobilidade parcial de ação. O corpo se torna o próprio expoente de luta, no qual todos os seus componentes de atividade merecem tanta atenção quanto sua deficiência. O contorno social de identidade de gênero, expressão de gênero, orientação sexual não pode ficar em segundo plano pois são tão constituintes desta individualidade quanto em qualquer outro. O corpo que a partir da própria vivência vai explicar a experiência a outros para que a sua inclusão seja possível, e apenas desta forma que poderá ser reconhecido já que sempre se torna cobaia de experimentos para tratamentos e qualquer forma de socialização, sempre a partir do olhar do outro e nunca dele próprio para com o outro. Este corpo como sujeito principal da socialização dos corpos desviantes para demonstrar que a despadronização ainda é mais frutífera que qualquer 
uniformização no valor à multiplicidade. Frida aponta que "A revolução é a harmonia da forma e da cor e tudo se concentra e move sobre a mesma lei = a vida = Ninguém está à parte de ninguém. Ninguém luta por si mesmo. Tudo é de todos e é um. A angústia e a dor, o prazer e a morte nada mais são que um processo para existir. $x x x x x$ a luta revolucionária $x x x x x x x$ neste processo é uma porta aberta para a inteligência" (KAHLO, 1995, p. 228).

Em vários momentos de sua obra, Frida Kahlo considera sua vivência tão específica como esclarecedora se problemas sociais ligados a questões de pessoas deficientes, de mulheres latino americanas, da política mexicana, de ancestralidade e colonialismo local. A partir de suas pinturas podemos considerar uma gama de componentes relativos a sua individualidade porém que determinam a realidade de uma época de transgressão muito importante para o mundo e para a arte. Mesmo que a relação conturbada com seu parceiro tenha tomado grande parte das discussões sobre a sua obra, Frida se mantém uma figura influente sobre os conceitos de feminismo da época e retomados atualmente contudo a condição de agravamento de sua deficiência, após o acidente que sofreu, deslocam as discussões para um viés patriarcal de uma exposição abstrata e imagética de questões que deveriam ser retomadas novamente pelas novas correntes do feminismo.

Através da bagagem feminista contemporânea, recheada por sua contribuição artística e de pessoa política pública, podemos reavaliar alguns conceitos perdidos pelo caminho - por se tratar de uma linguagem não verbal, ou poucas vezes escritas - mesmo assim abstratas pelo olhar do poeticidade, e transversalmente discutir questões de seu componente bissexual, e da deficiência como fator determinante para suas relações de afeto, e na análise de imagens e no ensino de artes com essa nova perspectiva, naturalizar outras linguagens expressivas desviantes trazendo uma representatividade inexistente até então por sonegação destas informações tão valiosas para o entendimento de sua obra, apreciação e integração de semelhanças a outros espectadores que não consideravam estes fatores e não se identificavam com a narrativa defendida sobre sua obra até então. 
Santos, A. C. S.; Pinheiro, A. M. M. P. B.

O Marxismo dará saúde aos doentes (1954). Frida Kahlo.

Em sua obra, O Marxismo dará saúde aos doentes, de 1954, Frida expõe que a sua potência e luta política por uma realidade mais igualitária, traz seu componente estético de pintura, no qual utiliza cores escuras e bem pigmentadas, demonstra sua ancestralidade mexicana através da sua vestimenta, e não

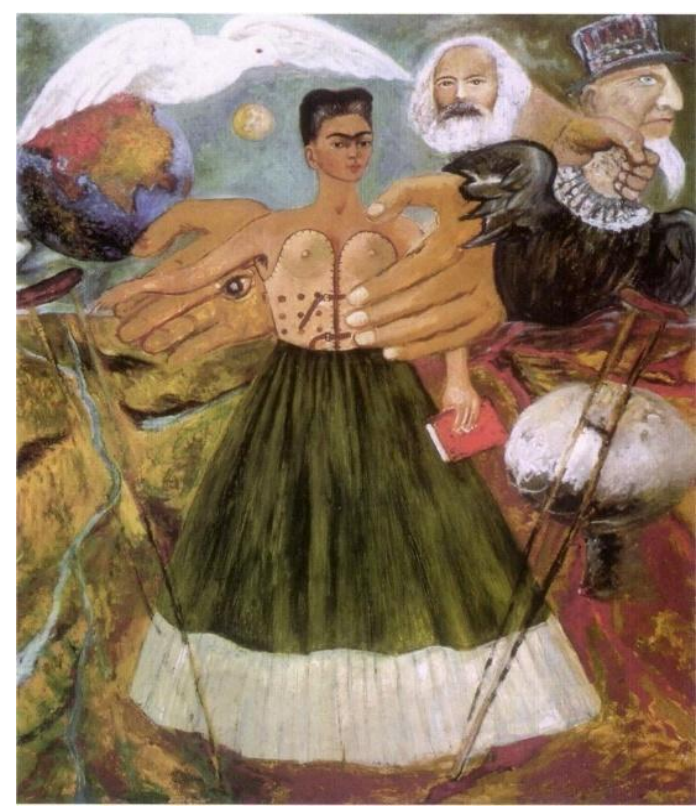

menos importante, insere elementos que descrevem sua condição deficiente e a esperança que uma ótica socialista seja amplamente inclusiva para as pessoas no mesmo estado que o seu. A permanente condição de doente traz à mente todas as intervenções cirúrgicas das quais Frida foi dependente para ter uma vida digna e produtiva, e a dicotomia vida e morte sempre presente nos seus pensamentos e obras. A amplitude mundial que o globo ilustrado defende na imagem antecede o ideal de globalização que temos em voga hoje. O livro vermelho em sua mão defende um posicionamento político inerente à sua condição deficiente e o real conhecimento sobre as teorias políticas para que seja eficaz uma mudança neste cenário. Ela, mulher, no centro da imagem, muda o protagonismo de teorias políticas para a centralização feminina.

1954 foi um ano de instabilidade mundial e da União Latina, organização internacional que reúne países de línguas nacionais românicas, ano de instabilidade no Brasil e suicídio do Presidente Getúlio Vargas e de levante militar no país, golpe militar sobre o governo do Paraguai e morte de Frida Kahlo. O enforcamento da águia com o rosto do Tio Sam comunica sobre a insatisfação do crescimento do capitalismo e da potência norte americana como referência de política mundial e toda dominação cultural que poderia significar este contexto histórico, pelo lado contrário a pomba da paz vindo de encontro por trás de Frida poderia preconizar seu falecimento e a paz eterna no fim do sofrimento de uma vida com tanta efusividade e dores corporais que demandavam uma insatisfação pela inadequação e imobilidade de sua condição final. 
Com tantos componentes teóricos que poderiam ser abordados através de uma única imagem, como poderíamos considerar Frida incapaz pelo seu elemento deficiente? A sua possibilidade de estudo de qualidade e de sentido familiar que não a considerava incapaz fez florescer toda sua potência subjetiva para que ela interferisse positivamente em gerações de pessoas e seu contexto deficiente tão mal aproveitado para potencializar a camada deficiente de seus espectadores nunca foi considerado um fator de poder. A competência em discernir fatores políticos sempre foi explicitada, porém sua vivência específica nunca se deu com importância suficiente para que fosse um elemento taxativo de virtude da sua personalidade. A estética adquirida e influenciadora de tantos artistas atuais sempre foi vista com pesar pelas pessoas que entendiam parte de sua condição, porém nunca como virilidade.

A sexualidade bissexual como posicionamento político sempre se deu por trás de uma desculpa de seus conflitos relacionais e mediante uma permissão aparente de seu parceiro, e nunca como definidora de necessidades individuais de sua personalidade.

Como considerado anteriormente, todos estes fatores componentes de sua subjetividade fazem com que Frida se afaste cada vez mais de uma imagem de incapacidade, mas ainda assim a mantém em um lugar de inadequação que invisibiliza muitos componentes de sua personalidade até hoje, tanto no meio fruidor de arte, quanto no ensino de artes visuais, mesmo com ela se tornando uma figura centralizadora de muitos conceitos feministas atuais.

A formação no ensino só será frutífera quando percebermos que os componentes que nos formam como cidadãos têm os aspectos embrionários desde a escola com tanta energia de mudança na época de escolaridade quanto a força que nos calcifica na vida adulta. E quem cria os tabus de discussão de qualquer assunto são os adultos que educam as crianças. Sem eles, não necessitaremos mais de aspectos transgressores de mudança, pois a pluralidade estará posta desde o início, sem determinações morais ou de julgamentos futuros. Os corpos terão suas amplitudes infinitas e suas configurações mutantes sem que sejam corrompidos pelo desejo de padronização. Procuramos um momento que seja determinado pelas vontades de afeto entre as pessoas e o sucesso através da felicidade e da busca individual por um coletivo potente e justo onde todos conviverão dentro de seus limites e apesar deles, onde o respeito 
seja a lei principal de acolhimento da alteridade. Todos seremos tão eficientes e diversos quanto os quereres indicam e os afetos não representarão mais conflitos ou medos, mas a expansão de consciências autônomas e preocupadas com o próximo. Kahlo (1995) ressalta,

Mas devo levar em conta que vivi doente desde os 6 anos de idade e que realmente por breves períodos da minha vida eu gozei verdadeiramente de boa saúde e por isso não fui útil ao meu partido. Agora em 1953, depois de 22 cirurgias me sinto melhor e poderei de vez em quando ajudar meu Partido Comunista já que não sou uma operária, já que sou uma artesã - e aliada incondicional do movimento revolucionário comunista. Pela primeira vez na vida minha pintura se propõe a auxiliar a linha traçada pelo Partido. Realismo Revolucionário (KAHLO, 1995, p. 240).

Se Frida entendesse a grandiosidade que suas imagens tomaram e o quão político o corpo dela se tornou, que através da sua vida e obra são discutidos capacitismo, inclusão, feminismo e arte, hoje ela estaria um pouco mais satisfeita, porque apesar do sistema capitalista ter se mantido, as minorias vivem para que ele se faça mais igualitário e que a equidade seja real em todos os locais sociais. Que o acesso vem sendo discutido e reafirmado a duras penas, mas cotidianamente pensamos formas de educação para diversas formas de deficiência sem que tenhamos que afastar socialmente essas pessoas e garantindo que a arte seja o meio de comunicação principal entre a educação e a inserção social de pessoas com deficiência.

Os sistemas educacionais e o mundo de mídia cada vez mais entende que representatividade importa e o ativismo que produziu este discurso mantém a discussão e através do conceito de representatividade, inserindo as pessoas deficientes no campo de conhecimentos e no campo acadêmico que antes não tínhamos este espaço por questão de acesso e revendo personalidades potentes e empoderadas como Frida, a colocando na condição de deficiente e demonstrando a crianças regulares e com deficiência que esses espaços são de todos, contanto que haja as mesmas oportunidades.

Frida e seu realismo revolucionário são cada vez mais contemporâneos de todas as pessoas que entendem a necessidade desta revolução para o melhor convívio e educação integrais. Cada vez mais real é a sua luta e se transforma em nossa luta cotidiana também, ao 
passo que neste momento escrevo para uma revista acadêmica e tenho políticas de acesso que me permitem chegar a estes locais de ensino, e retorno este conhecimento para educação de base, oportunizando que outras crianças deficientes se tornem adultos funcionais e profissionais respeitados. Ainda há um caminho longo pela frente, mas as vozes e os gestos e pensamentos de pessoas com deficiência crescem cada vez mais no Brasil e a despeito de todas as dificuldades continuamos seguindo.

A teoria Crip que Mello (2016) explica "A tradução do termo crip para a categoria de aleijado em português é uma forma de dar o mesmo sentido da palavra em inglês, revelando a zona de abjeção reservada às pessoas com deficiência no Brasil." (MELLO, 2016, p. 3266) revela tanto a característica de abjeção de corpos fora do padrão de beleza e saúde quanto a segregação destes corpos. Estamos diante a um Brasil de 2020 em meio a uma pandemia, onde os governantes aproveitam da ignorância política e educacional de seu povo para reduzir ao mínimo os seus direitos e relegar a vida das minorias, em especial aos deficientes que através da Política Nacional de Educação Especial, o presidente Jair Bolsonaro e seu Ministro da Educação Milton Ribeiro vão contra toda política de inclusão incentivada pelos governos anteriores, e permitem que as escolas regulares recusem a matrícula de alunos com deficiência para novamente segregá-los somente nas escolas especiais. Esse regresso de direitos diante todos os outros regressos neste momento do país é um sintoma de que a luta crip por reconhecimento de seus corpos e espaços ainda engatinha e se definir necessária é um dos passos mais importantes que estamos tentando garantir através dos estudos de educação e biopolítica (FOUCAULT, 2008).

Seguindo decreto 10.508/20 assinado por Jair Bolsonaro em 30 de setembro de 2020 a Política Nacional de Educação Especial além de ser um empecilho social para integração de pessoas com deficiência faz parte da necropolítica (MBEMBE, 2018) ressignificando Foucault onde "ser soberano é exercer controle sobre a mortalidade e definir a vida como a implantação e manifestação de poder."(FOUCAULT, 2008, p. 62) Logo, neste sentido, "a soberania é a capacidade de definir quem importa e quem não importa, quem é 'descartável' e quem não é."(MBEMBE, 2018, p. 41) E determina a morte dos deficientes dos ambientes públicos e seus 
direitos coletivos de ir e vir e habitar locais sem segregação. Todo o trabalho Lei Brasileira de Inclusão de 2015 e da Convenção Internacional de Direitos das Pessoas com Deficiência de 2007 está sendo jogado por água abaixo com uma lei retrógrada que segundo Bercito (2020) sobre o momento pandêmico atual diz que,

O sistema capitalista é baseado na distribuição desigual da oportunidade de viver e de morrer. Essa lógica de sacrifício sempre esteve no coração do neoliberalismo, que deveríamos chamar de necroliberalismo. Esse sistema sempre operou com a ideia de que alguém vale mais do que os outros. Quem não tem valor pode ser descartado (BERCITO, 2020).

Todo este cenário autoritário, preconceituoso e segregador põe a prova medidas de inserção social que vem sendo tomadas e garantem a inclusão de alunos com deficiências nos espaços públicos, porém em mínimos passos viraram de fato leis que garantem os acessos. E ao segregar apenas em escolas especiais estabelece a "criação de "mundos de morte", formas novas e únicas da existência social, nas quais vastas populações são submetidas a condições de vida que lhes conferem o status de "mortos-vivos". (MBEMBE, 2018, p. 71) onde a circulação de pessoas fora da normatividade biológica e intelectual determinada pela sociedade atual se torna um acinte, garantindo que apenas naquela escola especial ela tenha convivência com outros iguais.

De forma algum nego que a educação direcionada a qualquer especificidade pedagógica seja importante para a aprendizagem, porém esta seria uma didática direcionada a qualquer criança com diversas dificuldades de aprendizagem sendo estudante normativo, regular ou estudante com deficiência. O ideal para reforço acadêmico é sempre lidar com uma equipe especializada em momentos extraclasse e atendimento psicológico a todes - onde estudante, responsáveis pelo estudante junto a equipe pedagógica possam definir diretrizes para melhor aprendizagem possível. Enquanto o resultado da aprendizagem for sempre direcionado a boa colocação em vestibulares e processos seletivos sabemos, como sugere Mbembe (2018) que, 
Se poder ainda depende de um controle estreito sobre os corpos (ou de sua concentração em campos), as novas tecnologias de destruição estão menos preocupadas com inscrição de corpos em aparatos disciplinares do que em inscrevê-los, no momento oportuno, na ordem da economia máxima (MBEMBE, 2018. p. 59)

Mesmo com todo progresso que a Política de Inclusão teve nas escolas ao entender a importância do sentido geral da aprendizagem e socialização, a falta de recursos públicos financeiros e a carência de profissionais habilitados para uma pedagogia inclusiva de ensino principalmente por serem diretrizes atuais e os profissionais não serem incentivados a essa especialização, e também pela falta de contratos para estes funcionários - medidas restritivas de espaço e convívio não atingem positivamente nenhuma parcela da população. Sou professora no sistema público de ensino e acompanho diariamente a inclusão de estudantes com deficiência e a socialização com estudantes sem deficiência, mesmo sendo um desafio por causa deste sistema educacional tão escasso, vemos êxito para todos indivíduos que participam deste processo. O caminho da Política Nacional de Educação Especial empregada neste momento pode parecer um processo de especialização de ensino, mas não é. Ele se traduz em intolerância e descrédito de todos os profissionais que atuam na área, excludente e segregador, não é mais que uma desculpa para manter os Crip (MELLO, 2016) afastados e reforça uma impossibilidade pedagógica que não existe, porém é fomentada em nome de capacitismo (MELLO, 2016).

\section{O ensino de artes e 0 aprendizado de mundo}

A transgressão da arte sempre é relembrada em movimentos divergentes e em momentos políticos cruciais no mundo. Não seria diferente desta vez. Em um mundo globalizado e multimídia, a arte retoma seu lugar narrativo de identificar a atualidade e descrever as identidades da época em diversas situações culturais. E sobre o conceito de identidade no presente momento, York (2020) elucida, 
Mais uma vez, percebe-se que a identidade é um conceito polissêmico, que é, um conceito polissêmico, que é, também, empregado por distintas vertentes teóricas e campos disciplinares. Na ótica que assumo, no âmbito da cultura e da história, supõe que os sujeitos se fundem na co-criação de suas identidades. Entendendo, também, que os sujeitos teçam em si confluências múltiplas e distintas identidades (em gênero, raça, etnia, sexualidade, geração, alianças estratégicas, laços, parentalidade etc.), à medida em que são interpelados por diferentes situações, instituições ou agrupamentos sociais. (YORK, 2020, p. 42)

A arte além de criadora de narrativas e representante de identidades tem o poder de ensinar de forma não normativa conteúdos diversos e induzir a compreensão de temas distintos, além de ser grande aliada na coordenação motora em sua prática. Por isso ela se mostra tão importante, pois desvenda caminhos da mente desconhecidos e hoje é um dos principais atributos de ensino para formação dos alunos comuns, mas especificamente com os alunos com deficiência. A arte terapia como uma fusão do tratamento psicológico com o ensino de artes está presente em muitas escolas como um aparato muito valioso de compreensão do conteúdo e de seus estudantes, mostrando facilidades e dificuldades que estão presentes no aprendizado e utiliza-se a arte da melhor forma possível para o progresso do aluno e sua comunicação com o mundo. Apesar de qualquer termo relacionado a terapia ser engendrado junto à doença ou a deficiência, este é um termo muito mal empregado aqui no Brasil, por puro desconhecimento e falta de acesso da população em geral. Todas as pessoas seriam beneficiadas em muitas camadas caso o ensino básico fosse permeado pela arte terapia, além do ensino de artes já existente. Demonstramos assim que muitas das políticas que são direcionadas a população com deficiência seria de real valor a sociedade integralmente.

“A teoria crip (GAVERIO, 2016; MELLO, 2016), de mesmo modo, assume que não intenta em dividir o mundo entre pessoas deficientes e não deficientes, por todos serem deficientes em determinado aspecto ou sob outro relevo." (YORK, 2020 p.49). Esse entendimento que York nos traz da teoria Crip identifica a pluralidade dos corpos e sua incapacidade de padronização. E mais uma vez salienta a diversidade e todo o êxito em um mundo diversificado. Em uma realidade onde todes temos capacidades de aptidão diversas e complementares basta identificá-las e não deixar que impedimentos nos cancelarem de sabê-las. Na minha formação de Licenciatura em Artes, apesar de termos 
tido poucas disciplinas em educação especial - cabe melhor em uma especialização na área, sempre foi valorizado todas as subjetividades do aluno, incluindo as diferentes formas de aprendizado da arte e essa medida por essência inclui mais do que exclui. A divergência em formas de representação também é um grande ganho mesmo com pouca representatividade PCD nas imagens.

A minha experiência como professora de artes sendo uma pessoa com deficiência amplia todo um entendimento sobre rompimento de padrões e transgressão, e me permite muitas outros posicionamentos críticos quanto ao tema e sua prática. Imagens, práticas e debates já partem de um viés anti-capacitista e demonstram que qualquer estudante pode aprender diversas manifestações artísticas e ser bem sucedido nelas. A amplitude do fazer artístico possibilita um outro entendimento em relação a biologização do corpo e demonstra em seu produto final que as faculdades para a produção de pensamento não segregam nenhum tipo de pessoa, visto a obra de Frida, Bispo do Rosário, Aleijadinho etc. Longe de fomentar um discurso de superação, a arte consegue acolher panoramas diversos ou até contraditórios e mesmo assim validar todos eles, sendo o melhor campo para comunicabilidade de aptidões possível para inclusão e entrosamento entre estudantes e entre estudantes e equipe pedagógica.

\section{Teoria Queer, Ativismo Deficiente e Disability Studies}

A Teoria Queer, o Ativismo Deficiente e Disability Studies se relacionam sempre através da análise de normalidade, ou seja, na alteridade do normativo, discutem os padrões de normalidade social e confrontam o porquê de a sociedade mantê-los e não oportunizar nenhuma acessibilidade às pessoas que não estão contidas neles. Gavério (2017) explica sobre como este processo se deu,

Nesse sentido, o foco e a análise da normalidade (normalcy) indica um movimento critico análogo entre teoria queer, ativismo deficiente e disability studies. Por um lado, a proposta queer é pensar que a normalidade, nesse caso a heterossexualidade, se torna compulsória ao ser colocada como uma aparente escolha individual em que o contraponto em não 'escolhe-la' é ser 'anormal, desviante', homossexual. Por outro, a normalidade focalizada no debate crítico sobre deficiência refere-se à naturalidade e neutralidade com que o corpo 'não-deficiente' (able body) é posicionado. Em resumo, ambos 
movimentos teórico políticos estão preocupados em articular críticas às supostas naturalidades da normalidade que acabam a configurando como compulsória, como uma não escolha (GAVERIO, 2017, p. 108)

Hoje em dia o entendimento sobre o aspecto compulsório que é compreendido das normalidades faz rever toda a estrutura social capacitista (MELLO, 2016) onde as inteligências também partem de moldes gerados para a competitividade capitalista de produção e reprodução do capital, mercadologizando os corpos como meros produtores de riqueza e demonstrando que aquela forma adequada sugerida pelo padrão de normalidade é a geradora de sucesso.Cotidianamente na educação percebemos que este molde é maléfico a todos os participantes deste processo. O processo de aprendizagem tem mecanismos extensos para que todos possam ter a compreensão adequada se bem gerido junto da equipe pedagógica, equipe de saúde e aparato familiar. É importante ressaltar que todos estejam em consonância com as técnicas empregadas, os alcances sociais do tratamento e com o pensamento livre de preconceitos ou imposições. Esta deveria ser uma prática empregada em todos os estudantes, reafirmo. E mais uma vez deixo ressonante que os ganhos pelas mudanças sugeridas por essas teorias serão beneficiários a toda sociedade. Quando pensamos da micropolítica para a macropolítica pode parecer muito trabalhoso mudar a estrutura social de ensino para acolher uma parcela minoritária da população, mas quando entendemos que todas as mudanças que são feitas para acolher deficientes e a população queer, por exemplo, também acolheriam a população normativa, compreendemos a totalidade do benefício.

A amplitude de conhecimento sobre o outro, independente de quem seja este outro, compreende o mundo, e compreendendo o mundo faz-se totalizante sem necessidade de incluir ou excluir pois todes se sentirão acolhides e representades. E nesse sentido York (2020) coloca, "Naturalização refere-se, aqui, ao modo como as ideias, valores e regras sociais são transmitidos, justificados e adotados, como se fossem independentes da ação humana, como se fossem (im)posições naturais, que não podem ser evitadas, combatidas ou modificadas, sob o risco de alterarem essa ordem "natural" que garantiria a estabilidade e a reprodução da sociedade." (YORK, 2020, p. 50) 
Além das políticas todas de acesso é muito necessário que as pessoas todas se vejam a partir de suas qualidades, principalmente as pessoas com deficiência que já vem com um rótulo escrito frágil em qualquer ambiente que esteja. É interessante salientar que todos somos frágeis até um certo ponto e fortes em outros, sem que isso demande superação ou covardia, precisamos entender através da educação a possibilidade de humanizar e potencializar o indivíduo e formar uma sociedade melhor. A humanização e a potência não são e bem precisam ser opostos e não podemos adiar essa apreensão. Pessoa nenhuma merece ser congelada em um molde que os outros te colocam e ficar estática naquele conceito. E esta é uma experiência que toda pessoa com deficiência tenta se afastar, mas não consegue nunca como Gavério (2017) coloca a seguir,

Ter um defeito ou, depois, ter uma deficiência; ser um(a) defeituoso(a) ou, depois, ser um(a) deficiente significa, dentre outras coisas, possuir informações ambíguas, contraditórias sobre si; sobre como seu corpo deveria ser e não é ou como deveria funcionar/reagir de determinadas maneiras que não ocorrem. Informações que, muitas vezes, estão entre as considerações públicas e privadas em que determinados corpos, os deficientes nesse caso, estão imbricados (GAVÉRIO, 2017 p.97).

Nesse sentido sempre estamos perguntando sobre o que o corpo pode ou não sentir ou fazer e a demanda do próprio corpo sempre fica a cargo de outras pessoas. Não conseguimos confiar no nosso funcionamento ou demonstrar outras formas de fazer ou agir que outras pessoas vêm logo consertando para a normativa cada movimento físico ou intelectual que escolhemos fazer. É imprescindível que os movimentos sociais atuais incluam as pessoas com deficiência a todas as pautas pois há muito a ser discutido a partir da nossa própria visão.

Quando sinto a dificuldade de qualquer estudante a lidar com aceitação ou com dificuldade na produção artística procuro entender através de relatos do próprio qual é a dificuldade dele com o processo que está participando para conseguir fazer aquilo de outra forma, contudo agregar um bom resultado, que significa um resultado que todos fiquem satisfeitos. 
Parece aqui que estou falando mais do mesmo e que todos os educadores têm a preocupação com a assimilação de conteúdo para empoderar o cidadão e não para fazer uma avaliação ou prova. Não é verdade. Por falta de representatividade PCD nas equipes escolares outros professores não deficientes não percebem que a naturalização do corpo normativo transpassa qualquer teoria educacional vigente onde prioriza-se o padrão nos pensamentos, nos fazeres e nas produções. Quando estudantes não tem referência alguma de adultos com deficiência reforça a notoriedade de fragilidade e incapacidade, ou até de qualidade e expectativa de vida o que é problemático para qualquer pessoa com deficiência. Gavério (2017) entende que "Se ao longo dos anos 1970-80 a deficiência se torna uma identidade positivada politicamente, ela se positiva perante a vontade de participar da ordem que a excluía/oprimia como uma experiência legítima." (GAVÉRIO 2017 p. 102-103).

Todas as vezes que pretendemos a participação de pessoas com deficiência na sociedade são demandas das próprias pessoas com deficiência que pouco tem apoio das outras minorias ou da sociedade em si. Cada vez mais afastados dos cotidianos das pessoas não deficientes elas não sentem a necessidade de inclusão por causa do capacitismo instaurado em suas mentes. Diniz disserta sobre dizendo que "Deficiência é um conceito complexo que reconhece o corpo com lesão, mas que também denuncia a estrutura social que oprime a pessoa deficiente" (DINIZ, 2007, p. 7)

A inclusão de pessoas com deficiência na sociedade é completamente diferente da integração que existe hoje em dia, a integração demanda que as pessoas estejam em locais públicos que não são pensados para ela, a mercê de qualquer cuidado ou adaptação. Mais do que isso há a integração entre a população não deficiente, mas também não necessariamente há a inclusão. Vemos em inúmeros exemplos comuns no cotidiano que a inclusão relativa a cuidados sempre fica menosprezada, como por exemplo o cuidado de crianças sempre ser delegados às mulheres em locais públicos como fraldários onde os homens ficam excluídos deste cuidado por causa de uma estrutura social patriarcal e machista. Gonçalves Jr. (2018) repara que, 
modificar as histórias de abusos (muitas vezes trazidos como LGBTfobia pelos adolescentes) que ao meu redor se amontoavam, e que rotineiramente me fazem repensar a minha própria caminhada, é como se eu me tornasse a minha avó me auto aconselhando, sobre instâncias maiores e mais sutis do respeito (GONÇALVES JR,, 2018, p. 2).

A estrutura patriarcal na nossa sociedade mantém tantos preconceitos ligados ao cuidado do ser e a sexualidade que impede muitas interações saudáveis entre as pessoas não deficientes e especialmente entre pessoas com deficiência e sem deficiência, que mostra mais um entrave na convivência salutar em sociedade do que de fato um aspecto social. Quando vamos discutir o tema nas camadas das minorias sociais o problema aumenta consideravelmente transformando-se em violências variadas como psicológicas, físicas, morais e até patrimoniais.

Então o que de fato confere a uma sociedade a melhor integração e a real inclusão entre seus representantes? Acredito que temos sempre que pensar através da ótica do cuidado individual e coletivo. Perceber como aquela sociedade insere os seus cidadãos e considerar a importância que as pessoas têm para formar aquela malha social bem definida e que traz grandes benefícios para seu povo. Muitas vezes nos remetemos pensando em países de primeiro mundo e pensando no que poderíamos mudar para alcançar o tão sonhado desenvolvimento. Essa resposta é mais fácil que parece. Repare no que todos esses países têm em comum: Uma educação de base muito bem definida e extensiva a toda população. É a partir daí que toda a estrutura social se altera positivamente e o país se desenvolve. Com pessoas diversas e capazes. Independentes das áreas profissionais de escolha, todos participaram de uma educação inclusiva que gerencia o resto de suas vidas e confere a possibilidade a todos igualmente. Não adianta termos um sistema educacional que vá incluir o cidadão somente na faculdade ou no ensino fundamental. Este deve ser um trabalho de base muito bem definido e diversificado. Capacitar o indivíduo vai muito além de dar ferramentas a uma parcela, precisamos de meios, ferramentas e destino para esta capacitação.

Gavério (2017) coloca um ponto muito importante para começar a pensar a inclusão de forma potente, "Eu aprendi a ler e sentir meu corpo como um defeito e foi em torno desta categoria que minha infância foi modulada. O termo defeituoso parece 
carregar consigo um incômodo moral tácito, pois totalizaria um indivíduo como um todo problemático, como um todo incapaz." (GAVÉRIO, 2017, p. 110). Não vamos nunca conseguir incluir sujeitos que predispusermos com incapazes por definições biológicas. 0 início da inclusão parte daí, acreditarmos todes capazes e trabalharmos as qualidades de todes, inclusive as nossas.

\section{Referências}

BENHABIB, S. Situating the self. Gender, community and postmodernism in contemporary ethics. New York: Routledge, 1992.

BECKER, Howard S. Outsiders: estudos de sociologia do desvio. Rio de Janeiro: Zahar, 2008.

BUTLER, Judith. Problemas de gênero: feminismo e subversão da identidade. Rio de Janeiro: Civilização Brasileira, 2016.

BUTLER, Judith. "Por uma leitura cuidadosa". In: BENHABIB, Seyla; BUTLER, Judith; CORNELL, Drucilla; FRASER, Nancy. Debates feministas. Um intercâmbio filosófico. Trad. de Fernanda Veríssimo. São Paulo: Editora Unesp, 2018, p. 189-213.

COLLINS, Patricia Hill. Aprendendo com a outsider within: a significação sociológica do pensamento feminista negro. Sociedade e Estado, Brasília, v. 31, n. 1, p. 99-127, 2016.

DAVIS, Angela. Mulheres, raça e classe. Tradução de Heci Regina Candiani. São Paulo: Boitempo, 2016, 244p.

DINIZ, Débora. O que é deficiência? São Paulo: Brasiliense, 2007. (Coleção Primeiros Passos).

ELIAS, Norbert; SCOTSON, John L. Os estabelecidos e os outsiders: sociologia das relações de poder a partir de uma pequena comunidade. Tradução de Vera Ribeiro. Rio de Janeiro: Jorge Zahar, 2000.

FOUCAULT, Michel. Nascimento da biopolítica: curso no Collège de France (1978-1979). São Paulo: Martins Fontes, 2008.

FEDERICI, Silvia. Calibã e a bruxa: mulheres, corpo e acumulação primitiva. São Paulo: Editora Elefante, 2017.

FRASER, Nancy. Reconhecimento sem ética? Lua Nova, São Paulo, v. 70, p. 213-222, 2007.

GAVÉRIO, Marco A. Nada sobre nós, sem nossos corpos! O local do corpo deficiente nos Disability Studies. Revista Argumentos, Montes Claros, v. 14, p. 95-117, 2017. 
KAHLO, Frida. O diário de Frida Kahlo: um auto-retrato íntimo. Rio de Janeiro: José Olympio, 1995.

BERCITO, Diogo. Pandemia democratizou poder de matar, diz autor da teoria da 'necropolítica'. Folha de São Paulo, São Paulo, 30 mar. 2020. Disponível em:

https://www1.folha.uol.com.br/mundo/2020/03/pandemia-democratizou-poder-dematar-diz-autor-da-teoria-da-necropolitica.shtml. Acesso em: 30 mar. 2020.

MBEMBE, Achille. Necropolítica. 3. ed. São Paulo: n-1 edições, 2018.

MELLO, Anahi Guedes. Deficiência, incapacidade e vulnerabilidade: do capacitismo ou a preeminência capacitista e biomédica do Comitê de Ética em Pesquisa da UFSC. Ciência e Saúde Coletiva, Rio de Janeiro, v. 21, n. 10, 2016.

MATTOS, Sandra Maria Nascimento. Inclusão/exclusão escolar e afetividade: repensando o fracasso escolar das crianças de classes populares. Educar em Revista, Curitiba, n. 44, p. 217- 233, abr./jun. 2012.

VIEIRA, Elisabeth Meloni. A medicalização do corpo feminino. Rio de Janeiro: FIOCRUZ, 2015.

YORK, Sara Wagner. Tia, você é homem? Trans da/na educação: des(a)fiando e ocupando os "cistemas" de Pós-Graduação. 2020. 185 f. Dissertação (Mestrado) - Universidade Estadual do Rio de Janeiro, 2020.

GONÇALVES JR, Sara Wagner Pimenta. Corpos transgressores: Políticas de resistências. Campinas: Pontes, 2018 